\title{
PENGARUH KEDISIPLINAN, KOMITMEN ORGANISASI DAN MOTIVASI TERHADAP PRODUKTIVITAS KERJA KARYAWAN PADA PT PUTRA GEREM JAYA - MERAK
}

\author{
Suryaman ${ }^{1}$, Nindia $^{2}$ \\ Unserasuryaman15@gmail.com \\ Universitas Serang Raya
}

\begin{abstract}
ABSTRAK
Penelitian ini bertujuan untuk mengetahui kedisiplinan, komitmen organisasi dan motivasi terhadap produktivitas kerja karyawan pada PT Putra Gerem Jaya - Merak .

Metode yang digunakan adalah kuantitatif bersifat deskriptif dan asosiatif.Penelitian dilakukan di PT Putra Gerem Jaya-Merak pada bulan Agustus 2020 s.d Juli 2021. Populasi penelitian sebanyak 63 orang dengan menggunakan sampling jenuh. Data dikumpulkan dengan menggunakan instrument penelitian dan diolah menggunakan SPSS statistic versi 24.00 windows. Proses kedisiplinan, komitmen organisasi dan motivasi memiliki peran yang sangat penting untuk merealisasikan tujuan perusahaan yang optimal memerlukan sumber daya manusia yang berkualitas, namun pada kenyataannya berdasarkan observasi awal pada PT Putra Gerem Jaya - Merak produktivitas kerja saat ini pada kondisi rendah karena nilai rata-rata skor baru mencapai 30,3 standar skor 35, akibat ketelitian kerja karyawan dengan skor 19. Sehingga dapat dikatakan bahwa produktivitas karyawan masih kurang baik dan berhasil dalam pelaksanaannya

Berdasarkan hasil penelitian dapat disimpulkan bahwa: kedisiplinan berpengaruh tidak positif dan tidak signifikan, Sedangkan untuk komitmen organisasi dan motivasi berpengaruh secara positif dan signifikan baik secara parsial dan simultan sebesar $69 \%$ terhadap produktivitas kerja karyawan sedangkan sisanya dipengaruhi oleh faktor lain yang tidak diteliti.
\end{abstract}

Hasil penelitian ini merekomendasikan bahwa untuk meningkatkan produktivitas kerja karyawan dapat ditingkatkan melalui komitmen organisasi dan motivasi kerja karyawan

Kata Kunci : Kedisiplinan, Komitmen Organisasi, Motivasi ,Produktivitas Kerja Karyawan. 


\begin{abstract}
This study aims to determine discipline, organizational commitment and motivation to work productivity of employees at PT. Putra Gerem Jaya-Merak.

The method used is quantitative descriptive and associative. The research was conducted at PT. Putra Gerem Jaya-Merak in August 2020 to July 2021. The study population was 63 people using saturated sampling. Data were collected using research instruments and processed using SPSS statistics version 24.00 windows. The process of discipline, organizational commitment and motivation has a very important role to realize optimal company goals that require quality human resources, but in fact based on initial observations at PT. Putra Gerem Jaya - Peacock's current work productivity is in a low condition because the average score has only reached 30.3 standard score of 35 , due to the thoroughness of the employee's work with a score of 19. So it can be said that employee productivity is still not good and successful in its implementation
\end{abstract}

Based on the results of the study, it can be concluded that: discipline has no positive and insignificant effect, while for organizational commitment and motivation it has a positive and significant effect both partially and simultaneously by $69 \%$ on employee work productivity while the rest is influenced by other factors not examined.

The results of this study recommend that to increase employee productivity, it can be increased through organizational commitment and employee motivation.

Keywords: Discipline, Organizational Commitment, Motivation, Employee Productivity. 


\section{PENDAHULUAN}

Keberhasilan perusahaan dalam menjalankan usahanya tidak dapat terlepas dari faktor sumber daya manusia (SDM).Terlebih bagi sebuah perusahaan yang menawarkan jasa, .Casio (2017) menegaskan bahwa manusia adalah sumber daya yang sangat penting dalam bidang industri dan organisasi, oleh karena itu pengolahan sumber daya manusia mencakup penyediaan tenaga kerja yang bermutu, mempertahankan kualitas dan mengendalikan biaya ketenagakerjaan.Oleh karena itu, SDM adalah asset yang tak ternilai keberadaannya bagi satu perusahaan sehingga harus dipertahankan dan dihindari terjadinya turnover.

Keberhasilan perusahaansalah satunya ditandai dengan meningkatnya produktivitas.Produktivitas kerja yang tinggi merupakan salah satu keunggulan kompetitif perusahaan. Max Pangkey (2014: 1) dalam suatu penelitian menunjukkan bahwa setiap lembaga atau perusahaan terkait berupaya untuk mendapatkan karyawan yang memberikan prestasi kerja dalam bentuk produktivitas kerja yang tinggi untuk mewujudkan tujuan yang telah ditetapkan sebelumnya.

\section{TUJUAN PENELITIAN}

Berdasarkan permasalahan di atas tujuan yang hendak dicapai melalui penelitian ini adalah menguji besarnya:

1. Untuk mengetahui pengaruh kedisiplinan terhadap produktivitas kerja karyawan pada PT Putra Gerem Jaya.

2. Untuk mengetahui pengaruh komitmen organisasi terhadap produktivitas kerja karyawan pada PT Putra Gerem Jaya.

3. Untuk mengetahui pengaruh motivasi terhadap produktivitas kerja karyawan pada PT Putra Gerem Jaya.

4. Untuk mengetahui pengaruh kedisiplinan, komitmen organisiasi dan motivasi terhadap produktivitas kerja karyawan pada PT Putra Gerem Jaya.

\section{LANDASAN TEORI}

\section{Teori Kedisiplinan}

Menurut Mangkunegara (2013), disiplin kerja diartikan sebagai pelaksanaan manajemen untuk memperteguh pedoman-pedoman organisasi. Macam-macam disiplin menggunakan teoriMalayu $\mathrm{H}$. Hasibuandengan dimensi yaitu: 1).Tujuan kemampuan,2). Tingkat kewaspadaan, 3).Ketaataan standar kerja, 4). Etika kerja. Sedangkan indikator dari dimensiTujuan kemampuan yaitu : 1).Kehadiran pegawai tepat waktu ditempat kerja, 2). Intensitas kehadiran pegawai selama bekerja, untuk indikator dari dimensi Tingkat kewaspadaan yaitu: 1).Kewaspadaan dan hati-hati dalambekerja, 2).Menjaga dan merawat peralatan 
kerja danindikator dimensi dari ketaatan standar kerja yaitu : 1).Memiliki rasa tanggung jawab dalam bekerja, 2). Bekerja sesuai fungsi dan tugasnya, 3).Bekerja sesuai jam kerja.Sedangkan indikator dimensi dari etika kerja yaitu :1).Memiliki sikap dan perilaku yang baik dalam bekerja.

\section{Teori Komitmen Organisasi}

Menurut Robbins (2001) mendefinisikan komitmen pada organisasi yaitu sampai tingkat mana seorang karyawan memihak suatu organisasi tertentu dan tujuan-tujuannya, serta berniat memelihara keanggotaan dalam organisasi tersebut. Sedangkan teori yang digunakan sebagai alat ukur variable Komitmen Organisasi menggunakan teori Meyerand Allen 2010 dengan dimensi 1).Komitmen Afektif, 2).KomitmenBerkelanjutan, 3). Komitmen Normatif

Sedangkan indikator dari dimensi Komitmen Afektif 1).Keterikatan emosional karyawan, 2).Identifikasi 3).Keterlibatan dalam organisasi untukindikator dari dimensi komitmen berkelanjutan: 1). Kerugian bila meninggalkan organisasi, 2). Karyawan membutuhkan organisasi,Serta indikator dari dimensi Komitmen normatif: 1).Kesetiaan yang harus diberikan karena orang lain, 2). Kewajiban yang harus diberikan kepada organisasi.

\section{Teori Motivasi}

Menurut Hamzah B. Uno (2008 : 66-67) motivasi kerja merupakan motivasi yang terjadi pada situasi dan lingkungan kerja yang terdapat pada suatu organisasi atau lembaga. Sedangkan teori yang digunakan sebagai alat ukur variable motivasi adalah terori Menurut Hamzah B Uno (2009:72) dengan dimensi 1). Motivasi Internal 2). Motivasi Eksternal.

Sedangkan indikator dari dimensi Motivasi Internal yaitu : 1). Tanggung jawab dalam melaksanakan tugas, 2). Melakukan tugas dengan target yang jelas, 3). Memiliki tujuan yang jelas dan menantang, 4). Ada umpan balik atas hasil pekerjaan, 5). Memiliki rasa senang dalam bekerja, 6). Selalu berusaha bergaul dengan orang, 7). Diutamakan prestasi apa yang dikerjakan. Sedangkan indikator dari dimesni Motivasi Eksternal yaitu : 1). Selalu berusaha memenuhi kebutuhan hidup dan kerja, 2). Sering memperoleh pujian yang dikerjakannya. 3). Bekerja ingin memperoleh insentif.4).Bekerja dengan harapan ingin mendapatkan perhatian dari teman dan atasan.

\section{Teori Produktivitas Kerja}

Menurut Herny Simamora (2004) produktivitas kerja adalah keluaran tiap jam kerja dengan memperhatikan kulitas produk yang dihasilkan. Produktivitas bukan hanya sebagai hasil usaha manusia saja tetapi merupakan hasil kerja sama semua faktor yang digunakan dalam proses produksi yaitu modal, manusia, 
teknologi.Sedangkan teori yang digunakan sebagai alat ukur variable produktivitas kerja menggunakan teori Herny Simamora (2004: 612) dengan dimensi :1). Kuantitas, 2). Kualitas, 3). Ketetapan waktu

Sedangkan indikator dari dimensi kuantitas yaitu :1). Kecepataan dalam bekerja 2). Aktivitas yang diselesaikan.,Sedangkan indikator dari dimensi kualitas yaitu :1). Kecepataan dalam bekerja 2).Ketelitian dalam melakukan pekerjaan 3).ketepatan waktu dalam bekerja.Sedangkan indikator dari dimensi ketepataan waktu yaitu : 1). keterampilan dalam bekerja 2). Kecakapan dalam melakukan pekerjaan.

\section{HIPOTESIS PENELITIAN}

1. H-1 :Diduga Kedisiplinan terdapat perpengaruh positif dan signifikan terhadap produktivitas kerja karyawan.

2. H-2 :Diduga Komitmen Organisasi terdapat pengaruh positif dan signifikan terhadap produktivitas kerja karyawan

3. H-3:Diduga Motivasi terdapat pengaruh positif dan signifikan terhadap produktivitas kerja karyawan

4. H-4:Diduga Kedisiplinan, Komitmen Organisasi, dan Motivasi karyawan t4erdapat pengaruh positif dan signifikan terhadap produktivtas kerja karyawan.

\section{METODE PENELITIAN}

Pada penelitian ini penulis mengambil objek penelitian pada PT Putra Gerem Jaya - Merak. Penelitian ini dilakukan karena penulis ingin mengetahui seberapa besar pengaruh Kedisiplinan sebagai independen $\left(\mathrm{X}_{1}\right)$, Komitmen Organisasi sebagai independen $\left(\mathrm{X}_{2}\right)$ dan Motivasi sebagai independen $\left(\mathrm{X}_{3}\right)$ terhadap Produktivitas Kerjakaryawan sebagai variabel dependen (Y).

Adapun yang menjadi populasi dalam penelitian ini adalah karyawan PT Putra Gerem Jaya-Merak. Dengan jumlah 63 karyawan tetap. Dalam penelitian ini sampel yang digunakan oleh penulis adalah berdasarkan metode sampling jenuh, yaitu teknik penentuan sampel bila semua anggota populasi digunakan sebagai sampel (Sugiyono 2014:68).

Penelitian ini dilakukan melalui beberapa tahap yaitu, pertama : tahap konseptual difokuskan pada upaya untuk merumuskan dan membatasi masalah, peninjau kepustakaan yang relevan, mendefinisikan kerangka teoritis merumuskan hipotesis. Kedua : tahap penelitian mengidentifikasi populasi yang diteliti mengkhususkan metode untuk mengukur variable penelitian, merancang rencana sampling, mengakhiri dan meninjau rencana penelitian, melaksanakan pilot penelitian dan membuat revisi. Ketiga : mendesain instrument pengumpulan data 
penelitian dan model peningkatan kinerja karyawan dalam rangka meningkatkan kinerja secara berkelanjutan. Keempat : tahapan empiric dimana pada tahap ini dilakukan pengumpulan data dan penyiapan data untuk dianalisis, dan kelima : tahapan analitik yang memuat analisa data dan interprestasi hasil serta pengujian terhadap hipotesis yang telah disusun.

\section{HASIL DAN PEMBAHASAN}

\section{1) Uji Validitas dan Uji Reliabilitas}

Berdasarkan hasil uji validitas memperlihatkan bahwa nilai-nilai koefisien atau $r$ hitung untuk setiap variabel lebih besar dari nilai $r$ tabelnya, dengan demikian dapat dikatakan bahwa seluruh instrumen dalam penelitian ini bernilai valid. Hasil uji validitas instrumen penelitian seperti dilihatkan pada table dibawah ini.

Tabel 1

Hasil Uji Validitas

\begin{tabular}{|l|l|l|l|l|l|l|l|l|l|l|l|}
\hline Rtabel & 0,278 & 0,278 & 0,278 & 0,278 & 0,278 & 0,278 & 0,278 & 0,278 & 0,278 & 0,278 & 0,278 \\
\hline KD & 0,427 & 0,681 & 0,556 & 0,655 & 0,722 & 0,686 & 0,635 & 491 & & & \\
\hline KO & 0,507 & 0,644 & 0,623 & 0,558 & 0,663 & 0,696 & 0,627 & & & & \\
\hline MO & 0,521 & 0,632 & 0,509 & 0,675 & 0,701 & 0,674 & 0,608 & 0,692 & 0,702 & 0,720 & 0,572 \\
\hline PK & 0,574 & 0,785 & 0,647 & 0,543 & 0,486 & 0,646 & 0,575 & & & & \\
\hline
\end{tabular}

Sumber : Hasil Pengolahan Data SPSS V.23.

Berikut ini adalah Alpha hasil perhitungan menggunakan SPSS 23 untuk Variabel Kedisiplinan $\left(\mathrm{X}_{1}\right)$, Komitmen Organisasi $\left(\mathrm{X}_{2}\right)$, Motivasi $\left(\mathrm{X}_{3}\right)$ dan Produktivitas Kerja (Y) :

Tabel 2

\section{Perbandingan Nilai Alpha Dengan Nilai Standar}

\begin{tabular}{|c|c|c|c|}
\hline Variabel & Nilai Alpha & Nilai Standar & Kesimpulan \\
\hline $\mathbf{X}_{\mathbf{1}}$ & $\mathbf{0 , 7 5 2}$ & $\mathbf{0 , 6 0}$ & Realibel \\
\hline $\mathbf{X}_{\mathbf{2}}$ & $\mathbf{0 , 7 3 0}$ & $\mathbf{0 , 6 0}$ & Realibel \\
\hline $\mathbf{X}_{\mathbf{3}}$ & $\mathbf{0 , 8 5 0}$ & $\mathbf{0 , 6 0}$ & Realibel \\
\hline $\mathbf{Y}$ & $\mathbf{0 , 7 0 9}$ & $\mathbf{0 , 6 0}$ & Realibel \\
\hline \multicolumn{3}{|c|}{ Sumber $:$ Hasil Pengolahan Data SPSS } \\
\hline
\end{tabular}

Berdasarkan tabel di atas uji reliabilitas menggunakan metode alpha cronbach untuk tingkat konsistensi variabel $\mathrm{X}_{1}$ didapat nilai alpha sebesar 0,752 dan variabel $\mathrm{X}_{2}$ didapat nilai alpha sebesar 0,730 dan variabel $\mathrm{X}_{3}$ didapat nilai 
alpha sebesar 0,850 dan variabel $\mathrm{Y}$ diperoleh nilai alpha sebesar 0,709 hal ini berarti alpha yang diperoleh dari variabel adalah > nilai standar dan itu artinya bahwa seluruh pernyataan yang terdapat pada kuisioner dapat dinyatakan realibel.

\section{2) AnalisisDeskriptif}

\section{a. Kedisiplinan (X1)}

Deskriptif berdasarkan hasil tanggapan responden bahwa pada prinsipnya kedisiplinan $\left(\mathrm{X}_{1}\right)$ termasuk kategori baik karena mempunyai nilai rata-rata 251,75, sedangkan indikator dengan skor yang paling tinggi dengan skor 257 bagaimana seorang karyawan memiliki sikap dan perilaku yang baik dalam bekerja, tapi indikator yang memiliki nilai paling rendah yaitu 246 bagaimana seorang karyawan memiliki rasa tanggung jawab dalam bekerja dan 248 bagaimana seorang karyawan selalu mengutamakan kewaspadaan dan hati-hati dalam bekerja.

\section{b. Komitmen Organisasi (X2)}

Deskriptif berdasarkan hasil tanggapan responden bahwa pada prinsipnya Komitmen Organisasi $\left(\mathrm{X}_{2}\right)$ termasuk kategori baik karena mempunyai nilai ratarata 234, sedangkan indikator dengan skor yang paling tinggi dengan skor 242seorang karyawan tidak pernah merasa emosional terhadap organisasi ini, tapi indikator yang memiliki nilai paling rendah yaitu 229 perusahaan selalu memperhatikan kebutuhan karyawan dan 230seorang karyawan memiliki keterlibatan yang tinggi terhadap tugas/pekerjaan dan organisasi perusahaan.

\section{c.Motivasi (X3)}

Deskriptif berdasarkan hasil tanggapan responden bahwa pada prinsipnya motivasi $\left(\mathrm{X}_{3}\right)$ termasuk kategori baik karena mempunyai nilai rata-rata 247,63, sedangkan indikator dengan skor yang paling tinggi dengan skor 253seorang karyawan melakukan tugas dengan target yang jelas dan seorang karyawan sering memperoleh pujian yang dikerjakan, tapi indikator yang memiliki nilai paling rendah yaitu 237 seorang karyawan berharap mendapatkan perhatian dari teman dan atasan dan 245seorang karyawan selalu mengutamakan prestasi apa yang dikerjakan.

\section{d. Produktivitas Kerja (Y)}

Deskriptif berdasarkan hasil tanggapan responden bahwa pada prinsipnya produktivitas kerja karyawan (Y) termasuk kategori baik karena mempunyai nilai rata-rata 239,9, sedangkan indikator dengan skor yang paling tinggi dengan skor 253seorang karyawan dapat menyelesaikantarget dengan tepat pada waktunya, tapi indikator yang memiliki nilai paling rendah yaitu 232 seorang karyawan selalu teliti dalam pekerjaan yang diambil. 


\section{3) Analisis data struktural dan hasil hipotesis}

Analisis data pada 64 karyawan dengan menggunakan statistic SPSS 23.0 menghasilkan data dibawah ini yang dapat dilakukan untuk menganalisis selanjutnya (Pengajuan hipotesis).

Tabel 3

Coefficients $^{\text {a }}$

\section{Hasil Uji Regresi Linier Berganda}

\begin{tabular}{|c|c|c|c|c|c|c|}
\hline \multirow{2}{*}{\multicolumn{2}{|c|}{ Model }} & \multicolumn{2}{|c|}{$\begin{array}{l}\text { Unstandardized } \\
\text { Coefficients }\end{array}$} & \multirow{2}{*}{$\begin{array}{l}\text { Standardized } \\
\text { Coefficients } \\
\text { Beta }\end{array}$} & \multirow[t]{2}{*}{$\mathrm{t}$} & \multirow[t]{2}{*}{ Sig. } \\
\hline & & B & Std. Error & & & \\
\hline \multirow{4}{*}{1} & (Constant) & 11,327 & 4,036 & & 2,806 & ,007 \\
\hline & Kedisiplinan_X1 &,- 493 & ,266 &,- 580 & $-1,851$ & ,069 \\
\hline & $\begin{array}{l}\text { KomitmenOrganisasi_ } \\
\text { X2 }\end{array}$ & ,254 & , 110 & ,258 & 2,301 & ,025 \\
\hline & Motivasi_X3 & ,566 & , 191 & ,932 & 2,958 & ,004 \\
\hline
\end{tabular}

a. Dependent Variable: ProduktivitasKerja_Y

Sumber : Hasil Pengolahan Data SPSS 23

Tabel 4

Model Summary

\begin{tabular}{|c|c|c|c|c|}
\hline Model & $\mathrm{R}$ & R Square & Adjusted R Square & $\begin{array}{c}\text { Std. Error of the } \\
\text { Estimate }\end{array}$ \\
\hline 1 &, $557^{\mathrm{a}}$ &, 310 &, 275 & 2,72705 \\
\hline
\end{tabular}

a. Predictors: (Constant), Motivasi_X3, KomitmenOrganisasi_X2, Kedisiplinan_X1

Sumber : Hasil Pengolahan Data SPSS 23

Tabel 5

Uji Hipotesis Empat (F) Simultan

ANOVA $^{\mathrm{a}}$

\begin{tabular}{|c|c|c|c|c|c|c|}
\hline \multicolumn{1}{|c|}{ Model } & Sum of Squares & Df & Mean Square & F & Sig. \\
\hline \multirow{3}{*}{1} & Regression & 197,545 & 3 & 65,848 & 8,854 &, $000^{\mathrm{b}}$ \\
& Residual & 438,772 & 59 & 7,437 & & \\
& Total & 636,317 & 62 & & & \\
\hline
\end{tabular}

a. Dependent Variable: ProduktivitasKerja_Y

b. Predictors: (Constant), Motivasi_X3, KomitmenOrganisasi_X2, Kedisiplinan_X1 Sumber : Hasil Pengolahan Data SPSS 23 
Berdasarkan hasil pengolahaan Statistic SPSSVersi 23.0 dapat memperlihatkan hasil sebagai berukut :

\section{H-1 Diduga Kedisiplinan berpengaruh terhadapProduktivitas Kerja karyawan}

Nilai koefisien korelasi kedisiplinan bernilai sebesar 0,419 berada pada posisi kuat 0,40-0,599 dan mempunyai tingkat hubungan yang tinggi, artinya nilai kedisiplinan semakin meningkat maka produktivitas kerja (Y) akan semakin meningkat. Sedang berdasarkan Asosiatif dengan nilai hasil koefisien regresi variabel kedisiplinan $\left(\mathrm{X}_{1}\right)$ sebesar -0,493 bernilai negatif, sehingga dapat dikatakan bahwa kedisiplinan $\left(\mathrm{X}_{1}\right)$ tidak berpengaruh signifikan terhadap produktivitas kerja (Y). Setelah pengujian parsial dilakukan dan diperoleh $\mathrm{dk}=\mathrm{n}-2$ (63-2=61). Hipotesis dapat diterima jika $t_{\text {hiung }}>t_{\text {tabel }}$ berdasarkan tabel anova di atas, diperoleh untuk kedisiplinan adalah $t_{\text {hiung }}<t_{\text {tabel }}=(-1,851<1,999)$, dengan demikian hipotesis kedisiplinan tidak terdapat pengaruh yang siginifikan terhadap produktivitas kerja (Y) pada PT Putra Gerem Jaya. Sedangkan secara Deskriptif berdasarkan hasil tanggapan responden bahwa pada prinsipnya kedisiplinan $\left(\mathrm{X}_{1}\right)$ termasuk kategori baik karena mempunyai nilai rata-rata 251,75 ,

\section{H-2Diduga Komitmen Organisasi berpengaruh terhadapProduktivitas Kerja karyawan}

Nilai koefisien korelasi komitmen organisasi $\left(\mathrm{X}_{2}\right)$ bernilai sebesar 0,408 pada posisi kuat 0,40-0,599 dan mempunyai tingkat hubungan yang tinggi, artinya nilai komitmen organisasi $\left(\mathrm{X}_{2}\right)$ semakin meningkat maka produktivitas kerja $(\mathrm{Y})$ akan semakin meningkat., sedangkqan nilai Asosiatif bahwa koefisien regresi variabel komitmen organisasi $\left(\mathrm{X}_{2}\right)$ sebesar 0,254 bernilai positif sehingga dapat dikatakan bahwa komitmen organisasi $\left(\mathrm{X}_{2}\right)$ berpengaruh signifikan terhadap produktivitas kerja (Y).Setelah pengujian parsial dilakukan dan diperoleh $\mathrm{dk}=\mathrm{n}-2$ (63-2=61). Hipotesis dapat diterima jika $t_{\text {hiung }}>t_{\text {tabel }}$ berdasarkan tabel anova di atas, diperoleh untuk kedisiplinan adalah $t_{\text {hiung }}>t_{\text {tabel }}=(2,301>1,999)$, dengan demikian hipotesis komitmen organisasi $\left(\mathrm{X}_{2}\right)$ terdapat pengaruh yang siginifikan terhadap produktivitas kerja (Y) pada PT Putra Gerem Jaya.

\section{H-3Diduga Motivasi berpengaruh terhadapProduktivitas Kerja karyawan}

Hasil koefisien korelasi motivasi $\left(\mathrm{X}_{3}\right)$ bernilai sebesar 0,338 pada posisi kuat 0,20-0,399dan mempunyai tingkat hubungan yang tinggi, artinya nilai motivasi $\left(\mathrm{X}_{3}\right)$ semakin meningkat maka produktivitas kerja (Y) akan semakin meningkat. Sedangkan berdasarkan Asosiatif bahwa hipotesis 3 dengan nilai hasil koefisien regresi variabel motivasi $\left(\mathrm{X}_{3}\right)$ sebesar 0,566 bernilai positif sehingga dapat dikatakan bahwa motivasi $\left(\mathrm{X}_{3}\right)$ berpengaruh signifikan terhadap produktivitas kerja (Y),.Setelah pengujian parsial dilakukan dan diperoleh $\mathrm{dk}=\mathrm{n}-2$ (63-2=61). Hipotesis dapat diterima jika $t_{\text {hiung }}>t_{\text {tabel }}$ berdasarkan tabel anova di atas, diperoleh untuk kedisiplinan adalah $t_{\text {hiung }}>t_{\text {tabel }}=(2,958>1,999)$, dengan demikian hipotesis motivasi $\left(\mathrm{X}_{3}\right)$ terdapat pengaruh yang siginifikan terhadap produktivitas kerja $(\mathrm{Y})$ pada PT Putra Gerem Jaya. Sedangkan secara Deskriptif berdasarkan hasil 
tanggapan responden bahwa pada prinsipnya motivasi $\left(\mathrm{X}_{3}\right)$ termasuk kategori baik karena mempunyai nilai rata-rata 247,63 ,

\section{H-4Diduga Kedisiplinan, Komitmen Organisasi dan Motivasi berpengaruh terhadapProduktivitas KerjaKaryawan}

Berdasarkan Asosiatif bahwa hipotesis 4 dengan nilai hasil koefisien determinasi variabel kedisiplinan $\left(\mathrm{X}_{1}\right)$, komitmen organisasi $\left(\mathrm{X}_{2}\right)$ danmotivasi $\left(\mathrm{X}_{3}\right)$ secara simultan sebesar 0,310 (31\%) dan sisanya 0,690 (69\%) dipengaruhi oleh faktor lain yang tidak diteliti oleh penulis.Setelah pengujian simultan dilakukan, maka diperoleh df1 = k $-1(4-1=3)$ dan df2 = n $-\mathrm{k}$ (63-3=60). Hipotesis dapat diterima jika $F_{\text {hiung }}>F_{\text {tabel }}$ berdasarkan tabel anova di atas, diperoleh untuk produktivitas kerja karyawan $(\mathrm{Y})$ adalah $(8,854>2,76)$ dengan demikian kedisiplinan $\left(\mathrm{X}_{1}\right)$, komitmen organisasi $\left(\mathrm{X}_{2}\right)$ danmotivasi $\left(\mathrm{X}_{3}\right)$ secara bersama-sama terhadap produktivitas kerja karyawan (Y) pada PT Putra Gerem Jaya. Dengan demikian kedisiplinan $\left(\mathrm{X}_{1}\right)$, komitmen organisasi $\left(\mathrm{X}_{2}\right)$ danmotivasi $\left(\mathrm{X}_{3}\right)$ secara bersama-sama akan meningkat maka produktivitas kerja karyawan (Y) meningkat.

\section{SIMPULAN DAN SARAN}

\section{Simpulan}

Berdasarkan hasil analisis dan pembahasan, tentang Pengaruh Kedisiplinan, Komitmen Organisasi dan Motivasi terhadap Produktivitas Kerja Karyawan Pada PT Gerem Jaya-Merak, penulis menarik kesimpulan sebagai berikut :

1. Tidak terdapat pengaruh dan tidak signifikan antara Kedisiplinan $\left(\mathrm{X}_{1}\right)$ terhadap Produktivitas Kerja Karyawan (Y) pada PT Gerem Jaya-Merak.

2. Terdapat pengaruh positif dan signifikan antara Komitmen Organisasi $\left(\mathrm{X}_{2}\right)$ terhadap Produktivitas Kerja Karyawan (Y) pada PT Gerem Jaya-Merak.

3. Terdapat pengaruh positif dan signifikan antara Motivasi $\left(\mathrm{X}_{3}\right)$ terhadap Produktivitas Kerja Karyawan (Y) pada PT Gerem Jaya-Merak.

4. Terdapat pengaruh positif dan signifikan antara Kedisiplinan $\left(\mathrm{X}_{1}\right)$, Komitmen Organisasi $\left(\mathrm{X}_{2}\right)$ dan Motivasi $\left(\mathrm{X}_{3}\right)$ terhadap Produktivitas Kerja Karyawan $(\mathrm{Y})$ pada PT Gerem Jaya-Merak.

\section{Saran}

1. Pada prinsip Kedisiplinan termasuk kedalam kategori "baik". Namun yang perlu di pertahankan yaitu kehadirpegawai ditempa kerja selalu tepat waktu dan bekerja sesuai dengan fungsi dan tugasnya, sedankan yang perlu ditingkatkan agar mengutamakan kewaspadaan dalam bekerja dan hati-hati dalam bekerjauntuk meningkatkan tanggung jawab dalam bekerja. 
2. Untuk Komitmen Organisasi sebagai $X_{2}$ termasuk kedalam kategori "baik" Namun yang perlu di pertahankan yaitu -pengendalian emosional pegaqwai terhadap organisasi dan kepercayaan pada perusahaan sangat tinggi , sedankan yang perlu ditingkatkan agar perhatihan perusahaan terhadap kebutuhan pegawaidan meningkatkan keteribatan kerja pada perusahaan.

3. Untuk Motivasi sebagai $\mathrm{X}_{3}$ termasuk kedalam kategori "baik". Namun yang perlu di pertahankan yaitu hubungan kerja antar karyawan dan memberikan penghargaan dan pujian pada Karyawan,sedangkan yang perlu ditingkatkanagar penilaian prestasi kerja dan perhatian dari rekan kerja dan atasan.

4. Untuk Kinerja Pegawai, sebagai Y termasuk kedalam kategori "baik". Namun yang perlu di pertahankan yaitu tingkat ketelitian kerja dan penyelesaian target kerja di perusahaan, sedangkan yang perlu ditingkatkan yaitu agar meningkatkan hasil kerja. 


\section{DAFTAR PUSTAKA}

Rivai, Veithzal .(2009) manajemem sumber daya manusia untuk perusahaan. Jakarta : PT RAJAGRAFINDO PERSADA.

Hasibuan, Melayu S.P. (2007) manajemen personalia dan sumber daya manusia.Jakarta : PT. Bumi Askara.

Fahmi Irham . (2013) manajemen Kinerja .Bandung :Alfabeta

Munandar, Ashar Sunyoto . (2008) psikologi industry dan organisasi.Jakarta : Univeristas Indonesia

Labudo ,Yusritha . (2013) "Disiplin kerja dan kompensasi kerja pengaruhnya terhadap produktivitas kerja karyawan PT. Sinar Galesong Pratama cabang Manado".

Rismalasari . (2014) "Pengaruh Motivasi Terhadap Produktivitas Kerja Karyawan Pada PT. Sermani Steel Makassar".

Setiawan, Nashrudin, Muharram Ritonga, Husni (2017) "Pengaruh Pengawasan,

Lingkungan kerja dan komitmen kerja terhadap produktivitas kerja DI UNIVERSITAS PEMBANGUNAN PANCA BUDI MEDAN".

Agustin , Novianti . (2015) "Pengaruh Budaya Organisasi, Kepemimpinan

Dan Komitmen Terhadap Produktivitas Kerja Karyawan (Studi Pada PT Astra International Tbk Daihatsu Cabang Majapahit Semarang)".

Abdullah , Dudung . (2017) "Pengaruh Komitmen organisasional dan lingkungan psikologis terhadap produktivitas kerja karyawan BANK BJB CABANG MAJALENGKA".

Usman, Ismail. (2016) "Pengaruh disiplin kerja terhadap produktivitas kerja karyawan pada PT ALLO JAYA DIBONTANG".

Sitanggang ,Resnawa, Rezki ,Prana Riadia , Wahyudi, Dedi. (2015) "Pengaruhmotivasi dan disiplin terhadap produktivitas kerja karyawan di PT.RUBYCON INDONESIA".

Desi Rahmawati (2013) "Pengaruh motivasi terhadap produktivitas kerja karyawan PT FAJAR BERLIAN TULUNGAGUNG". 